ISSN: 2572-2921

Volume 2, Issuse 1,18 pages

\title{
Action Plan Towards the Information Society in Developing Countries and the Arabic Speaking World
}

\author{
Dr. Ramadan Elaiess \\ Department of information studies, University of Benghazi, Libya \\ ramadan.elaiess@uob.edu.ly
}

Abstract

Research Objectives: The purpose of this paper is to sheds new light on the importance of information and communication technology infrastructure and its significant role in establishing an information-based society. It intendeds to focus on the current state of ICT infrastructure in developing countries and discuss its potency and influence on enhancing the competitiveness and productivity that needs to be improved in order to foster the total economy of those countries. It will also concentrate on the digital divide between advanced countries and third world nations. This paper aims to accomplish another goal related directly to Action Plan that might be formulated to lead to an information society in developing countries and the Arabic speaking world. This, in turn, will reflect positively on the economy of developing countries and assist in establishing the targeted knowledge - based society as a forward step.

The objective of this paper is to draw an outline for the transition route which should take place in developing countries in order to establish an information - based society as the transition route has become a compulsory corridor and not a matter of choice. It is also essential to point out in this context that this paper will suggest different ways and approaches that might assist the Arab states in the transition course by implementing policies and strategies derived from the recommendations of the World Summit on the Information Society.

Methodology / Approach: The design of this paper is based on different tools such as personal readings of intellectual production, literature review, experience, and the insights of other researchers and experts in the scope of ICTs. In addition to that, the paper is also based on the recommendations of the World Summit on the Information Society which was held in two phases. The first phase took place in Geneva during 2003 and the second in Tunis during 2005. The main objective of WSIS was to bridge the digital divide between developing and developed countries and to promote the creation of an equitable and all-inclusive information society.

Research Implications: This paper may assist ICT policy makers as well as information policy makers in the third world countries to develop innovative guiding principles that position ICT infrastructures and information technology applications such as E-learning, E-business, E-commerce, E-health, E-government and so on, as a part of a strategic plan. This, in turn, is expecting to assist in solving a lot of problems associated with weakness of access to up-to-date information required for improving the current situation and to encourage the adoption of ICT in those countries.

Originality / Value: This paper adds new information and deepens understanding of a significant issue. It is the first of its kind to provide information and considerable insights on the current scenario of ICT infrastructures in developing countries. It indicates also existing obstacles, barriers, difficulties, suggestion, and recommendations for further development.

Findings and Conclusion: The paper reveals that effective adoption of ICT in developing countries will accelerate the level of knowledge acquisition and consequently improve national development. The paper also concludes with a proposal for developing and enhancing the current scenario by adopting some programs that can facilitate achieving the targeted goals and highlights important policy considerations relevant to ICTs infrastructure development.

Keywords: Information-based Society, ICT in Developing Countries, World Summit on the Information Society. 


\section{INTRODUCTION}

The post-industrial society, now termed as information society is characterized by using information as an economic source. Where institutions and companies exploit information and make use of it by increasing their efficiency and effectiveness as well as increase the target for the improvement and development of the total economy of the state. Since the sixties of the last century, economics scientists have added a fourth sector to the three primaries known sectors that are Agricultural, Industry, and Services, i.e. the sector of information, since the production of information, preparation, treatment, and dissemination to their users has become the main economic activity in many countries of the world.

Moreover, in the last decades, it was noted that radical changes have been made in the economic, political, and social powers because of depending basically on the Intellectual technology which includes new commodities and services that mainly rely on information as an investment source and a strategic good, national income source and a field for the labor force.

Perhaps one of the most outstanding aspects of the contemporary society is changing from an economy of industries to an economy of information and from a national economy to a world comprehensive economy or a world integrated economy, and changing from producing goods and manufacturing commodities to producing information.

While this is the current scenario in the developed countries, there are many indicators which have pointed out that the developing countries have not participated in the industrial revolution as well as globalization. There are also negative indicators on participating the third world countries in the information revolution which will reflect badly on their foreseeable future if they do not act as quick as possible since knowledge is critical for sustainable development and for the evolution of social, economic, and intellectual life.

In fact, currently, the world is divided between the haves and have-nots or the information rich and the information poor. As a consequence, it can be classified into three main categories that are developed or advanced nations, less developed countries, and developing countries and each category comprise some countries. "The United Nations has identified nearly thirty countries in Africa and Asia that are exceptionally poor and lack development prospect. Yet more than three-quarters of the 190 members of the United Nations are ranked as developing" (United Nations, 2012)

This indicates that the majority of countries in the world are suffering from poor information and communication technology infrastructure which need to be improved to cope up with the developed nations and to narrow the gap between them and advanced countries. In addition, the statistical profiles of the least developed countries published by the United Nation Office of the High Representative for the LDCs, LLDCs and SIDS WWW.UN.org/ohrlls/ depict that the least developing countries accounted for over $11 \%$ of the world's population ( 742 million) in 2004 , but only 0.6 of the world's GDP. A Low per capita income, low levels of human assets and a high economic vulnerability characterize these countries, which need specific support;

- to develop their physical infrastructure and human resources;

- to enhance their institutional capacities and

- to reduce their competitive disadvantage in the globe.

\section{THE WORLD SUMMIT ON THE INFORMATION SOCIETY WSIS}

The World Summit on the Information Society (WSIS) was held in two phases. The first phase took place in Geneva during 2003 and the second in Tunis during 2005. The main objective of WSIS was to bridge the digital divide between developing and developed countries and to promote the creation of an equitable and all-inclusive information society 
It is important to mention here that there are different barriers and obstacles counter by developing countries and hinder their participation in the current knowledge - based society. The following points are just as follows:

1. Shortage and weakness of ICT infrastructure, which consists of various components such as telecommunication networks and access to stable electricity.

2. Lack of national information policies.

3. High cost of ICT and low quality of telecommunication.

4. Underdeveloped IT industry.

5. Inadequate access to the Internet.

6. General low literacy levels.

7. Language barrier, most content is in English, not local language.

8. Absence or inadequate locally relevant content.

9. Low level of computer education, scarcity of trained instructors.

10. Lack of locally available trained manpower for operation and maintenance support.

11. Inadequate investment in ICT infrastructure, and general resource crunch.

12. High cost of terminal equipment (PCs)

13. High cost of Internet access, unaffordable by large section of population.

The above mentioned barriers must be taken into consideration to assist developing nations to overcome the obstacles which hinder their participation in the current information age and to bridging up the digital divide which remains wide.

\section{LITERATURE REVIEW}

The term digital divide was coined in the 1990s to describe the growing gap between those who have access to and the skills to use ICT and those who have limited or no access. In other words, it is the gap between the haves and have- nots, or the information rich and the information poor. The digital divide is an umbrella term used to describe the deficiency of technological access and/or the lack of possession of technological hardware or software. The reason for escalating this phenomenon might due to one or some of the followings:

1. Social factors :

- Literacy skills

- Disability vs. fit

- $\quad$ Age: old vs. young

2. Economic factors :

- Developing nations vs. Advanced countries

- Poverty, i.e. unaffordability

- Lack of international investment and funding

3. Cultural factors

- Family background (income and education )

- $\quad$ Ethnicity and language (non English speaking ) 


\section{Action Plan Towards the Information Society in Developing Countries and the Arabic Speaking World}

4. Geographical factors

- Rural areas vs. Suburban

- Underdeveloped nations vs. developed nations

5. Approach factors

- Fear of technology

- $\quad$ Lack of motivations

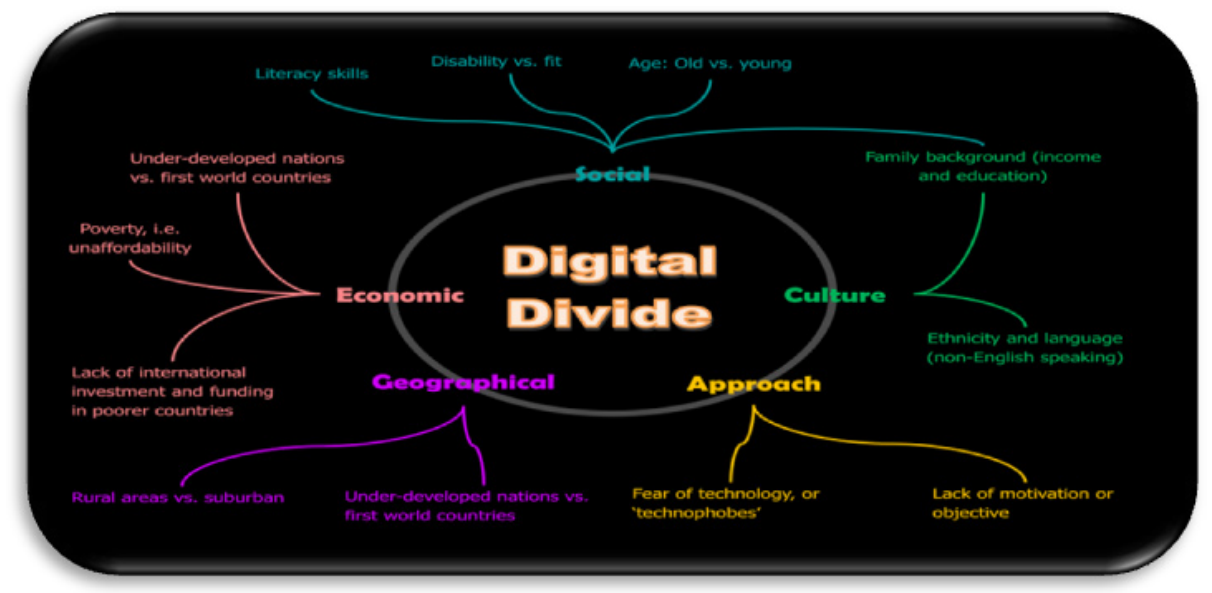

Fig 1. showing the digital divide factors

In addition, "individuals find themselves excluded from technology as a result of lack of education, skills, public access points, confidence, and awareness of what the technology can actually do for them" http://www.icthub. org.uk/articles/Digital_Divide.html

The digital divide between countries could be demonstrated with the Digital Access Index (DAI) which is a global index for benchmarking a country's progress, in the overall ability of individuals in a country to access and use ICTs. (ESCWA, 2014)

There was a particular concern that ICT would exacerbate existing inequalities, therefore different and comprehensive studies were conducted in order to ascertain the extent to which the current digital divide has reached and the negative influence of this phenomenon in particular on less developed countries and developing countries which account for more than two third of the world population. Continuing to explore the literature written on digital divide resulted in knowing that the digital divide phenomenon has been sometimes exaggerated and sometimes belittled. However, the digital divide phenomenon does not exist only in the third world. In fact, it does also exist in developed countries but in different rates and shapes. It is affecting so many citizens worldwide. According to the latest findings of published research papers on the subject which illustrate the digital divide and its impact on academic achievement, it can be clearly seen that even in the USA, the same phenomenon still exist through various socio-economic factors that impacts the academic achievement due to the relationship between technology accessibility and achievements although it is very much complicated by other compounding factors such as the subject of learning, use of technology, and socio-economic condition.( Russell, 2006).

The European Union suffering also from the same phenomenon (Sjaak, 2005) states that after the first of May 2004, when the EU was enlarged from 15 to 25 member states, the digital divide in the EU widened substantially owning to the national connectivity which vary from less than ten percent to more than sixty percent. This 
Action Plan Towards the Information Society in Developing Countries and the Arabic Speaking World

was caused by regional lack of technological factors. Therefore, it was recommended that traditional means of dissemination of information should be maintained and furthered as a consequence of the anticipation that inequality on internet-connectivity in the UE will increase dramatically. The United Kingdom is another example of the same phenomenon. (Chowdhury, 2004) reported that "in Britain, more than $60 \%$ of the richest $10 \%$ of the population have household access to the internet, whereas among the poorest $10 \%$, only $6 \%$ have household access to the internet". Moreover, one third of adults in the UK have never used the Internet not necessarily because of economic issues but rather owing to several factors such as education, skills, and confidence.

\section{Current State of InTernet Usage in African Countries}

The impacts of ICT on the economic performance and trade competitiveness of developing countries is significant, therefore there is an urgent need for each country to draw its information policy and to interpret this policy into action, owing to the importance of ICT infrastructure which contribute heavily in the transition process to an information economy. There is also a need to draw the ICT policy framework, which should highlight the priorities of providing information for health and education as well as for remote specialists and researchers, and also to assist in creating commerce for small and medium business.

It is a fact that in some developing regions the number of Internet users has grown substantially as the UN report 2015 announced (http://www.unctad.org) but overall the gap between developed and developing countries remain wide. Additionally, the quality of connections is just as important as their number. While some countries have seen spectacular growth in broadband access there are still large variations worldwide.

The following table illustrates Internet usage in Africa and the rest of the world, being a real challenge issue that must be handled as a sensitive concern to avoid keeping those nations left in the cold, especially the least developed countries as they are facing more risk of failing to come out of poverty.

Table 1. Showing Internet usage statistics for Africa and the rest of the world

(Source: IWS, March-2017)

\begin{tabular}{|l|l|l|l|l|l|}
\hline AFRICA REGION & $\begin{array}{l}\text { Population } \\
\text { (2017 Est.) }\end{array}$ & $\begin{array}{l}\text { Pop. \% } \\
\text { of World }\end{array}$ & $\begin{array}{l}\text { Internet Users, } \\
\text { Latest }\end{array}$ & $\begin{array}{l}\text { Penetration } \\
\text { (\% Population) }\end{array}$ & $\begin{array}{l}\text { Internet } \\
\text { \% Users }\end{array}$ \\
\hline Total for Africa & $1,246,504,865$ & $16.6 \%$ & $\mathbf{3 4 5 , 6 7 6 , 5 0 1}$ & $27.7 \%$ & $9.3 \%$ \\
\hline Rest of World & $6,272,524,105$ & $83.4 \%$ & $\mathbf{3 , 3 8 6 , 2 9 6 , 9 2 2}$ & $54.0 \%$ & $90.7 \%$ \\
\hline WORLD TOTAL & $\mathbf{7 , 5 1 9 , 0 2 8 , 9 7 0}$ & $\mathbf{1 0 0 . 0} \%$ & $\mathbf{3 , 7 3 1 , 9 7 3 , 4 2 3}$ & $\mathbf{4 9 . 6 \%}$ & $\mathbf{1 0 0 . 0} \%$ \\
\hline
\end{tabular}

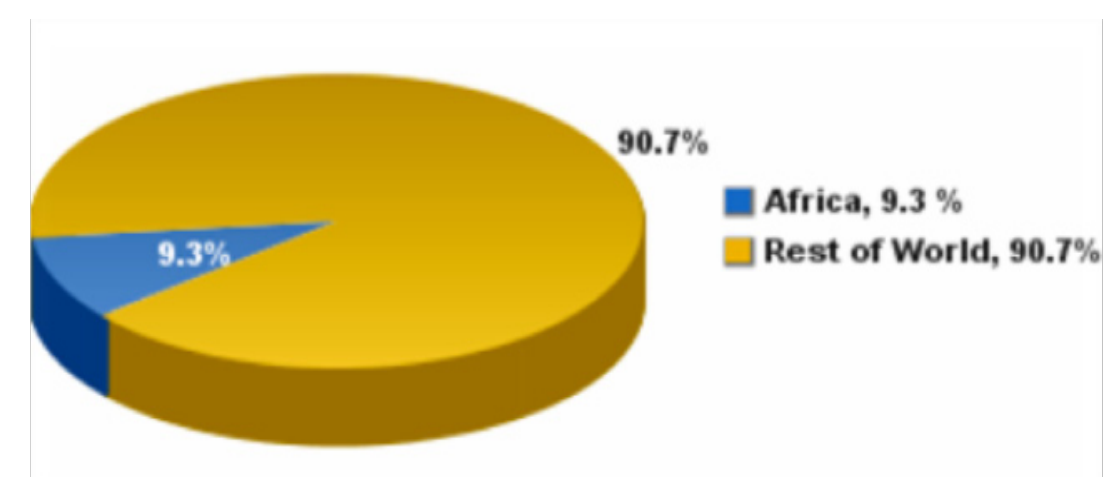

Fig 2. Showing the African percentage of Internet users compare to other continents

( Source: IWS, March-2017) 
Although some developing countries which are striving to catch up with the more advanced nations have changed their strategy towards information policy after recognizing the importance of participation in the so-called Information age. Many other developing countries are still wrestling to improve their primitive ICT infrastructure, which need to be enhanced to be able to take part and to participate in the current revolution. However, chances are still available and changes can be made if those countries are willing to exploit the new technological revolution to the maximum and to make use of the information technology that is considered as the base of any development in the contemporary society.

\section{GLOBAL CONCERN}

To overcome the problems related to information infrastructure in the developing countries and less developed countries, the United Nation has arranged many different approaches to assist those countries to leapfrog to the rank of developed nations by adopting some programs that can help in achieving the targeted goals. This was addressed in Geneva declaration of principles and Tunis commitment (World summit on the information society, 2006). "The Summit aimed at reducing the digital divide between developed and developing countries by increasing awareness of the benefits of the information society, and by presenting mechanisms to assist developing countries and third world countries to advance towards such a society". (ESCWA, 2014)

The following are some of the assurances, which have been_brought in both the summits:

- We emphasize that the adoption of ICTs by enterprises play a fundamental role in economic growth. The growth and productivity enhancing effects of well-implemented investments in ICTs can lead to increased trade and to more and better employment. For this reason, both enterprise development and labour market policies play a fundamental role in the adoption of ICTs. We invite governments and the private sector to enhance the competence of Small, Medium and Micro Enterprises (SMMEs), since they furnish the greatest number of jobs in most economies. We shall work together, with all stakeholders, to put in place the necessary policy, legal and regulatory frameworks that foster entrepreneurship, particularly for SMMEs.

- We also recognize that the ICT revolution can have a tremendous positive impact as an instrument for sustainable development. In addition, an appropriate enabling environment at national and international levels could prevent increasing social and economic divisions and the continuous widening of gap between rich and poor countries, regions, and individuals-including between men and women.

- We also recognize that in addition to building ICT infrastructure, there should be adequate emphasis on developing human capacity and creating ICT applications and digital content in local language, where appropriate, so as to ensure a comprehensive approach to building a global Information society

- We recognize that equitable and sustainable access to information requires the implementation of strategies for the long-term preservation of the digital information that is being created.

- We reaffirm our desire to build ICT networks and develop applications, in partnership with the private sector, based on open or interoperable standards that are affordable and accessible to all, available anywhere and anytime, to anyone and on any device, leading to a ubiquitous network.

- We reaffirm our strong resolve to develop and implement an effective and sustainable response to the challenges and opportunities of building a truly global Information Society that benefits all our peoples.

- We strongly believe in the full and timely implementation of the decisions we took in Geneva and Tunis, as outlined in the Tunis Agenda for the Information Society.

The above-mentioned recommendations call attention to four major phases which should be implemented to overcome the deterrents and obstacles that face the advancement of the third world countries and these are as follows:

American Research Journal of Computer Science and Information Technology Page 6 
- Adoption of Information and Telecommunication Technology which considered being the cornerstone required for supporting the process of the transition to the information society. Therefore, it is strongly recommended.

- Developing of human capacity by designing of training programmes and workshops in order to improve information literacy.

- Establishment of national information policies to enhance the current state of information infrastructure.

- Establishment of digital content and long-term preservation strategies of the information created, purchased, and harvested in a digital form.

\section{Action Lines of the World Summit on the Information Society}

1. The role of public governance authorities and all stakeholders in the promotion of ICTs for development.

2. Information and communications infrastructure

3. Access to information and knowledge

4. Building confidence and security in the use of ICTs

5. Enabling environment

6. ICT Applications

- E-government

- $\quad$ E- business

- E- learning

- E- health

- E- employment

- E- environment

- E-agriculture

- E- science

7. Culture diversity and identity and local content

8. Media

9. Ethical dimension of the information society

10. International and regional cooperation

\section{Partnership}

The Action Plan relies on partnerships of all stakeholders: Governments, the private sector, the civil society, and regional and international organizations, and cooperation at national and regional levels in a collaborative, constructive and mutually supportive manner with the aim of building the information society in the Arab region.

\section{Vision and Mission}

The Action Plan attempts to translate the vision into practically achievable actions to attain short, medium, and long term objectives of building of an information society in the Arab region, in which highly-developed ICT networks, equitable and ubiquitous access to information, appropriate content in accessible formats and 
Action Plan Towards the Information Society in Developing Countries and the Arabic Speaking World

effective communication can help people to achieve their potential, promote sustainable economic and social development, improve quality of life for all, alleviate poverty and hunger, aid education and health, and facilitate participatory decision-making processes. (ESCWA, 2014)

It can be clearly seen from the ongoing that both conventions are considering ICT applications as the right path for success and one of the essential instruments for the advancement of the developing countries. Therefore, essential care should be taken towards these newcomers especially for nations seeking to improve their information infrastructure which will play a considerable role in enhancing their total economy gradually, since many scholarly studies have proved that there is a correlation between the developments being achieved in developed countries and their dependence on the information sector. They also have demonstrated the significant growth of the GNP (Gross National Production) in different countries having adopted the strategy of information industry in Europe and Asia and how successful were these strategies.

Although there has been a debate about whether the information technology revolution is paying off in higher productivity, decade of studies at the firm and country levels has consistently shown that the impact of IT investments on labour productivity and economic growth is significant and positive as (Derrick, 2013)has stated in his research paper which has critically reviewed more than 50 studies whose results have been published in peer-viewed scholarly journals. In addition, Francesco Daveri also reported that "the return to growth of the US economy in the 1990s and in particular its growth acceleration in the second half of decade are mostly credited to the increased contribution of information technologies". (Daveri, 2011)

It is important here to point out that IT in this context can be divided into two main areas that are IT- producing and IT-using sectors. Therefore, a distinction has to be made between both areas. While the IT -producing sector contain the manufacturing of computers, semiconductors or telecommunications hardware or provide software and services that enable these technologies to be used effectively in organizations. The IT- using sectors are all other sectors of the economy i.e. Agriculture sector, industry sector, or services sector that apply IT as part of their operations in order to achieve greater efficiency and effectiveness. (Derrick, 2013)

\section{Action Plan and Roadmap for the Transition Process}

\section{Defining the Information Society}

To begin with let us first define what an information society is? There are various definitions of the information society; however, all of them consist of the same principles. For instance, Information society can be defined as "a society in which information becomes the main product or essential to other products, with a recognition that organizations success depends on the ability to exploit information, and most workers depend on information flow to perform their jobs. In practice, information is heavily dependent on computerized processes and the internet".(www.csa.com/hottopics/internet/gloss.php). It can be also defined as a type of society in which information and information access play a central role, economically, socially and individually. Governments are making efforts to bring countries into this era. mobileman.projects.supsi.ch/glossary.html. It can be concluded from the former definitions that everyone in the information society participates in the process of handling of information as a producer or as a consumer and access to information is also available to everyone. Moreover, in information society, there is no hindrance or barriers to delivering information anytime and anywhere to people who need it to satisfy a specific request or need. Furthermore, peoples in information- based society exploit information to the maximum and develop their economy by using information as an economic source and finally Information - based society generates knowledge - based economy. The information society can be measured by exploring citizens' access to and use of the internet, e-government, e-learning, e-health, buying and selling on-line and e-business readiness. 
Action Plan Towards the Information Society in Developing Countries and the Arabic Speaking World

Fixing the Wrong Notion and Strategy

The world has witnessed successive revolutions begun with the pastoral and agricultural revolution followed by the industrial revolution of the $19^{\text {th }}$ century until the information revolution which termed now as the information age. Strategies and priorities have also changed in every revolution and stage according to the lived period. One can easily notice when browsing all what have been written on developing countries that priorities in those countries were always the basic human needs which comprise food, water, health, hygiene, transportation, and electricity as though developing countries could not get out of this circle and have just to concentrate on how to solve these barriers and related problems. This is actually what can be considered as the wrong notion and the wrong strategy. These countries have to put ICT infrastructure on the top of their priorities list otherwise they will never solve their problems and will not accomplish any significant achievement. Generation after generation in developing countries have grown up with the notion that their problems lies in how to solve the problems of basic needs. The barriers to development will never be resolved through providing water or food. The barriers to advancement will be solved when those countries take real action against poverty. The problems will be solved by planning and understanding of key underlying issues and by investigating what are the real obstacles and deterrents to advancement. Take Malaysia for example. This country advanced from a third world country to developed nation status in less than two decades. The country's economy was agricultural based and subsequently shifted towards manufacturing. (Olan, 2002) states that "computer and high-tech technology has been at the core for this transition and the country was successful in attracting some high tech companies such as Motorola, Dell, and Intel. Because of this strategy, Malaysia now ranks among the world's largest suppliers of semiconductor". Malaysia has embarked the next phase which is beyond manufacturing and toward becoming a knowledge-based society. This vision and strategy can serve as a model for undeveloped countries.

There is still much hope for developing countries to catch the last train and to participate in the information age. Several steps should be taken in the transition phase. It should be taken into consideration that there is a need to develop ICTs policy and information policy in each country considered among this category in the first stage. In fact, this is the most important issue. Without information policy all the efforts that could be paid for the transition process to an information society would be worthless unless there is a policy designed specifically for supporting and sustaining the overall achievements which suppose to take place as a result of the transition to an information society and exploitation of what is available for free over the world.

Difficulties may arise, however, when an attempt is made to implement the ICT policy. As approaches of this kind carry with them various well-known limitations and difficulties at an early stage. Nevertheless, step by step such barriers could be overcome.

\section{Second Step: Defining Information Society Components}

1. The components of information society consist of the following items:

2. Powerful ICT - computers and networks

3. Divers of information resources - printed and electronic

4. Financial support to support and sustain the ongoing process.

5. ICT training - IT literacy

6. A set of local digital libraries 
Action Plan Towards the Information Society in Developing Countries and the Arabic Speaking World

7. A number of adequate libraries and information centres

8. Information literacy programs.

The following will cover these points in details and these components will be discussed solely.

\section{Powerful ICTs}

To begin with there is a need to point out that computers in the developing countries are not scarce as one might think (Witten, 2002). In fact, a considerable number of developing countries are now manufacturing personal computers and also export such goods and commodities to other developing countries such as Libya, Egypt, and Tunisia. The prices of computers are also decreasing because of users ambitions to the latest. According to International Telecommunication Union, the total telephone access in developing countries increased from $2 \%$ 1n 1991 to 81\% in 2014. Internet usage has grown also rapidly in developing country. (http://wwwitu.int/) These indicators show that there is a steady progress in ICTs in developing countries. However this does not mean that the gap between advanced countries and developing countries is narrowing. On the contrary the gap is widening owing to several factors. To assist these countries overcome the ICT shortage, there is a need to set up a plan that encouraging this industry. This plan must cover the following points:

- Opening this sector to local and international companies with minimum barriers.

- Providing incentives to all players to compete in global market.

- Invest in human resources

- Promoting competition and internet-friendly regulatory policies are an important component of addressing the issue (Wellston, Scott 2013) Regulation and internet use in developing countries.

- Financial support is critical for supporting local enterprises in order to be able to compete.

\section{IT Literacy and Training}

IT literacy is one of the important issues in developing countries. It is a major problem faced a considerable number if not all undeveloped countries. A plan has to be set to eradicate this phenomenon. Decision makers who are responsible for drawing this action plan should take in to consideration that time and money is needed as well as hard look of the future of such a preparation. The advantage of such a strategy will take place after a period of time.

Because of the high cost of IT training courses, Arab countries have to rely on some freely provided programs from some organization. Here are some of these programs which resulted from good gestures to help people.

Programs for the Enhancement of Research Information (PERI) is a program providing support to developing countries. (This program makes all training materials free to download, and encourage local adaptation and use of these materials. The workshops cover such topics as; Electronic Information Resources for Health Workers; Electronic Journals and Electronic Resources Library Management; Introduction to Using the Internet; Licensing and negotiation skills; Monitoring and evaluation of e-resource use; PC Troubleshooting for Library Personnel; Train the trainer; Web Page Design and Authoring; Working together to support research: optimizing the use of e-resource)

This program was designed to assist undeveloped countries to overcome IT literacy and to encourage the adoption of ICT in those countries. The website for this program is available at: http://www.inasp.info/peri/ countries.shtml. The list of eligible countries which can benefit from this program is provided below. 
Action Plan Towards the Information Society in Developing Countries and the Arabic Speaking World

\begin{tabular}{|c|c|c|}
\hline 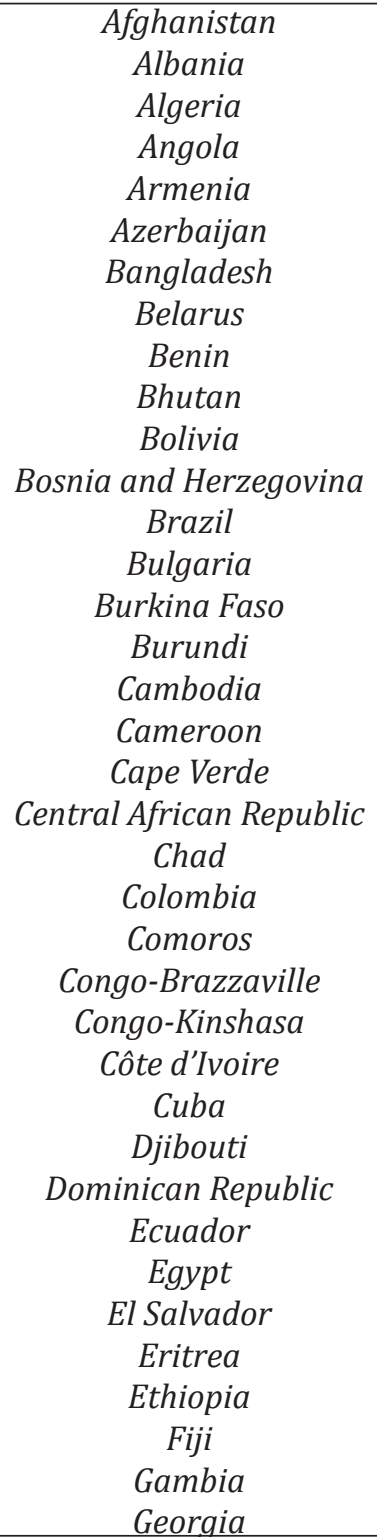 & $\begin{array}{c}\text { Ghana } \\
\text { Guatemala } \\
\text { Guinea } \\
\text { Guinea-Bissau } \\
\text { Guyana } \\
\text { Haiti } \\
\text { Honduras } \\
\text { India } \\
\text { Indonesia } \\
\text { Iraq } \\
\text { Jamaica } \\
\text { Jordan } \\
\text { Kazakhstan } \\
\text { Kenya } \\
\text { Kiribati } \\
\text { Korea, Dem.Rep. } \\
\text { Kyrgyzstan } \\
\text { Laos } \\
\text { Lesotho } \\
\text { Liberia } \\
\text { Macedonia } \\
\text { Madagascar } \\
\text { Malawi } \\
\text { Maldives } \\
\text { Mali } \\
\text { Marshall Islands } \\
\text { Micronesia, Fed. Sts. } \\
\text { Mauritania } \\
\text { Moldova } \\
\text { Mongolia } \\
\text { Montenegro } \\
\text { Morocco } \\
\text { Mozambique } \\
\text { Myanmar } \\
\text { Namibia } \\
\text { Nepal } \\
\text { Nicaragua }\end{array}$ & $\begin{array}{c}\text { Niger } \\
\text { Nigeria } \\
\text { Pakistan } \\
\text { Papua New Guinea } \\
\text { Paraguay } \\
\text { Peru } \\
\text { Philippines } \\
\text { Rwanda } \\
\text { Sao Tome and Principe } \\
\text { Senegal } \\
\text { Serbia } \\
\text { Sierra Leone } \\
\text { Solomon Islands } \\
\text { Somalia } \\
\text { Sri Lanka } \\
\text { Sudan } \\
\text { Surinam } \\
\text { Swaziland } \\
\text { Syria } \\
\text { Tajikistan } \\
\text { Tanzania } \\
\text { Thailand } \\
\text { Timor Leste } \\
\text { Togo } \\
\text { Tonga } \\
\text { Tunisia } \\
\text { Turkmenistan } \\
\text { Uganda } \\
\text { Ukraine } \\
\text { Uzbekistan } \\
\text { Vanuatu } \\
\text { Vietnam } \\
\text { West Bank and Gaza } \\
\text { Western Samoa } \\
\text { Yemen } \\
\text { Zambia } \\
\text { Zimbabwe }\end{array}$ \\
\hline
\end{tabular}

Source: Program for the Enhancement of Research Information http://www.inasp.info/peri/countries.shtml

Apart from the former program there is a need to design IT courses that can be offered for free to students in secondary schools, colleges, and universities. These courses have to focus on the importance of IT and how can people benefit using IT in daily life. The following IT course is a very good course model to be provided in developing countries. (Olan, 2002)

\section{Disscusion TOPICS}

The following is an outline of potential disscusion topics for the course:

\section{Information Technology in the Developing World}

a. Current impacts ( positive and negative )

- Political 
- Social

- Economic

b. Who is involved in IT development efforts

- Governments

- Multinational corporations

- Aid agencies and non-profits

c. Information technology and sustainable human development

- New global marketplaces

- Information for everyone

- High tech shops

d. The digital divide

- Information rich and information poor countries

- Infarstrcture needs

- Empowring people vs. controlling people

\section{Other Related Technologies}

a. Telcommunications

- Telephon systems

- Wireless

- Satellite

b. Tele-Medecine

c. Manufacturing and support industries

The above mentioned program might raise some questions about how could third world countries initiate these course programs. Is there sufficient qualified manpower that are professional in IT? The answer is yes, there are enough IT skilled professional in almost all developing countries. Those professionals are able to provide the above mentioned programs if they were willing to assist in the transition process.

\section{Digital LibRARIES}

I believe it is important to reaffirm here again the recommendations of the World Summit on the Information Society with regard to digital libraries when it has emphasized on the creation of local digital content (We also recognize that in addition to building ICT infrastructure, there should be adequate emphasis on developing human capacity and creating ICT applications and digital content in local language, where appropriate, so as to ensure a comprehensive approach to building a global Information Society)

"Digital libraries can assist human development by providing a mechanism for distributing information on priorities and materials that address specific community problem besides benefit from methods of information distribution". (Witten, 2006)

There is a need in the developing countries to start building local digital libraries. The benefit of establishing such electronic libraries is considerably massive and well known. Therefore, the following section will briefly shed lights on digital libraries and explain what kind of services could be provided through these libraries. 
Action Plan Towards the Information Society in Developing Countries and the Arabic Speaking World

Building Low - Cost Digital Libraries

There is no doubt that traditional publishing in developing countries has failed in achieving its obligations and duties towards readers and scholars because of the obstacles that had to be overcome in order to pave the way for this sort of publishing. Some of these problems, for instance, the high cost of printed copies and the long time it takes to be distributed coupling with the obsolesce of some knowledge disciplines. Users in developing countries face regularly difficulty in getting up to date information for undertaking their research work which usually reflect negatively on research activities.

Building low-cost digital libraries are becoming uncomplicated thanks to the availability of free software required for building low-cost digital library. Nowadays, various software such as Greenstone and Dspace are available for free. The Greenstone software was produced to build New Zealand digital library, afterwards became free to assist developing countries building their local digital libraries to contribute in providing suffice and adequate information to satisfy the needs and requirements of library users anywhere. The software provides a new way of organizing information and making it available over the Internet or on CD-ROM.

\section{Information Resources for Local Digital Library}

There is considerable number of free resources on the web. These resources are free to use by anyone and anywhere in the world. Librarians and information professionals can add what they think is might useful for their users to their local digital library. In addition, there are also government publications that can be disseminated through the digital library. I will point out in the following section to some freely accessible resources on the Internet and how can users benefit from the vast amount of information through the local digital library.

It is worth to mention in this context that there are also several information resources available on the web through subject gateways and virtual libraries. These are mentioned in Gobinda Chowdhury paper which published in 2004 titled Digital divide: How can digital libraries bridge the gap? (Chowdhury, 2004) pointed to several subject gateways that are very useful if information professionals involved in building the local digital library choose the appropriate one and make it accessible to their users by pointing to the website from their own page.

Examples of subject gateways:

-Business and economics: http://bized.ac.uk

-Social science: SOSIG. http://www.sosig.ac.uk

Fig 3. provides some specialized digital libraries that can be built to present services for end users in developing countries.

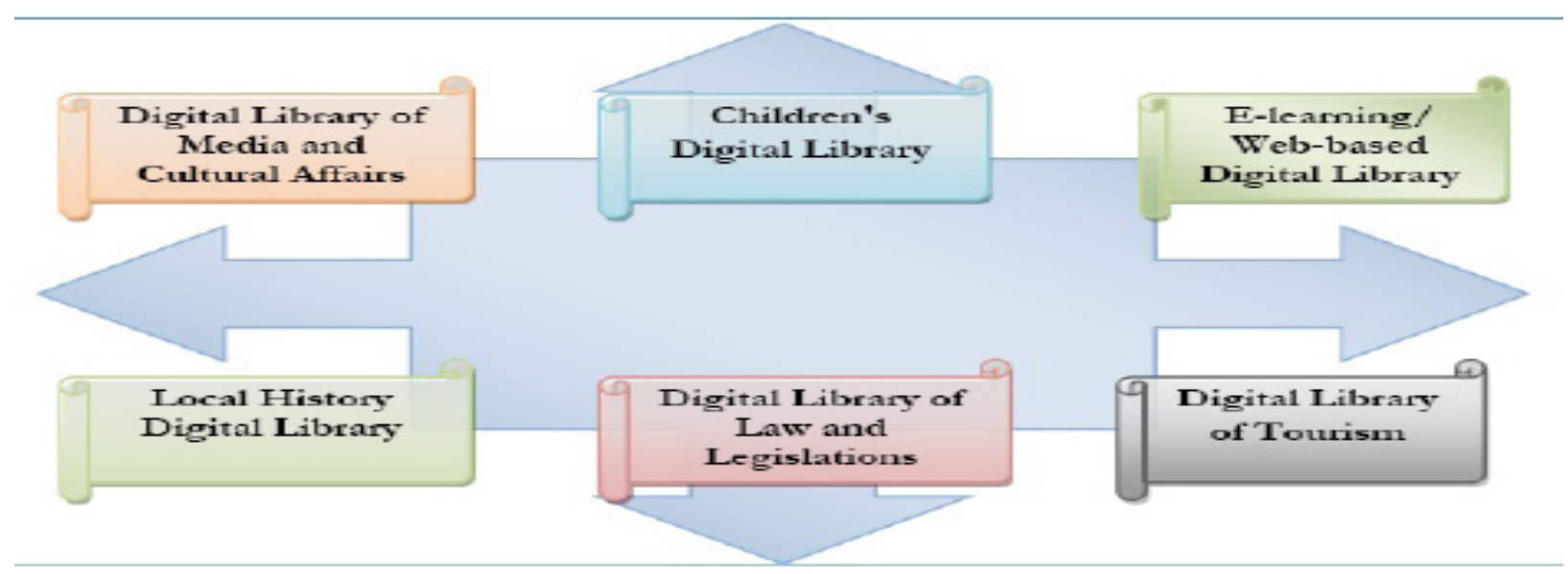

Fig 3. Various types of digital libraries 
Action Plan Towards the Information Society in Developing Countries and the Arabic Speaking World

A Number of Adequate Libraries and Information Centres

The importance of libraries and information centres is immense to provide information resources for the scientific community within universities and higher institutions in developing countries. The development of all aspects of life depends mainly on research and development which rely on some different component. The utmost significant factor in this domain is up to date information resources that keep scholars informed about the latest in their field of studies.

The following e-books and e-journals are available for free on the web and can assist research workers and scientists in developing countries to cope up with all information resources in their scientific fields. I will point out firstly to some freely accessible e-books on the Internet.

\section{Free e-books}

There are a number of free e-books in the field of medicine and health science. Most of these books are published between $2000-2012$.

\section{Free books for doctors}

The AMEDEO Group is now making many important medical textbooks available online, free and in full-text. Currently, 600 titles are included in the service, sorted by specialty and title. Free Books for Doctors also provides a free alert service as new titles are added. http://freebooks4doctors.com/

\section{On- line books}

Online Books is a website that facilitates access to 20,000 books that are freely readable over the Internet. It also aims to encourage the development of such online books, for the benefit and education of all. Users can search and browse by New Listings, Author, Title and Subject. http://onlinebooks.library.upenn.edu/

\section{Gutenberg digital library}

There are 20,000 free books in the Project Gutenberg. All these books are free to download. http://www. gutenberg.org/wiki/Main_Page

\section{Digital Mathematics Library}

This digital library contains links to 1822 digitized mathematics books. http://www.mathematik.uni-bielefeld. de/ rehmann/DML/dml_links.html

\section{Tips Club e-books}

Provide free e-books to download http://ebooks.tipsclub.com/

\section{The Arabic Library}

Provides free e-books on various subjects ranging from general works to geography and history. It covers also applied and pure science.

Books on literature are also available to download. http://abooks.tipsclub.com/

\section{Classic Bookshelf}

An electronic library provides access to classic books for free. available at: http://www.classicbookshelf.com/ library/

- The Directory of Open Access Journals (https://doaj.org/) with almost 10.000 peer-reviewed journals.

- The Directory of Open Access Books (https://www.doabooks.org/) with almost 9.000 academic books

- The network of Academic Institutional Repositories of scientific papers, for which the Open Access Metadata Harvesting Protocol allows to set up harvesters that collect the metadata (including URL-links). 
Action Plan Towards the Information Society in Developing Countries and the Arabic Speaking World

Best example of such harvester is BASE, the

- Bielefeld Academic Search Engine (https://www.base-search.net/), collecting the metadata of almost 115 million document from more than 5.000 academic sources. $60 \%$ of these documents are freely accessible worldwide.

- The OA medical information delivered by the US National Institute of Health with their Medline and PubMed Central archives.

- Google Scholar, which also searches through all these repositories.

- Research4life (http://www.research4life.org/) has set up 4 special collections available for some developing countries.

- Two worldwide organizations that help university libraries in these problems are EIFL and INASP. You mention both of them, but

\section{E-Journals}

One of the most important factors in the transition process depends on the availability of information resources for scholars and research workers. Most of the Universities and higher education institutions in the Arab speaking world suffering from a lack of up to date resources due to shrinking budget or to some related reasons. To be able to reach the targeted level of user satisfaction, librarians and information professionals involved in the collection management need to be aware of the rage of organizations and institutions that provide free accessible sources on the web. The amount of free e-journals on the net is noticeable. A considerable number of free e-journals are nowadays freely accessible to encourage scientific research everywhere and to assist scholars from poor countries to cope up with the latest in their fields by providing up to date information resources.

The following websites provide free accessible e-journals; however, the list below is not exhaustive since the purpose of this paper is not to provide full details of free web resources but rather to give general idea about how can information professionals assist users in getting up to date information resources.

PERI which stands for Programme for the Enhancement of Research Information provides information resources and support for third world countries, so every country listed in the former list which covers eligible countries have the right to reap the advantages of free information resources through subscription. The following is just a sample of the available free resources for some countries. The list below comprises On-line full- text and Databases offered to Sudan. It is a current list of the online information resources available through the PERI Program to librarians and researchers in not-for-profit institutes throughout Sudan.

On-line Full Text Journals and Databases

American Physical Society

American Physical Society has agreed to partner with INASP to make their electronic content available at no charge to education, research and not-for-profit organizations in Sudan.

\section{Annual Reviews}

Analytic reviews in 32 focused disciplines within the Biomedical, Physical and Social Sciences.

\section{BeechTreePublishing}

Beech Tree Publishing has agreed to partner with INASP to make their electronic content available at no charge to education, research and not-for-profit organizations in Sudan.

Mary Ann Liebert Inc.

55 authoritative publications in the most exciting and promising areas of biomedical research, clinical medicine, surgery, law, and science. 
Action Plan Towards the Information Society in Developing Countries and the Arabic Speaking World

Multilingual-Matters

Multilingual Matters has agreed to partner with INASP to make their electronic content available at no charge to education, research and not-for-profit organizations in Sudan.

\section{Oxford Journals}

Over 170 leading titles in science, technology, medicine, humanities, and social sciences.

\section{OxfordUniversityPress}

Oxford University Press has agreed to partner with INASP to make their electronic content available at no charge to education, research, and not-for-profit organizations

\section{African Journals Online}

Tables of Contents and abstracts of over 200 African journals with document delivery.

\section{AGORA}

Free or low-cost access to major scientific journals in agriculture and related biological, environmental and social sciences for public academic institutions in developing countries.

\section{EIFL}

eIFL.net is an independent foundation that strives to lead, negotiate, support and advocate for the wide availability of electronic resources by library users in transition and developing countries.

\section{HINARI Phase 1}

Free access to 2300 biomedical and related social sciences journals and other resources for health sector and academic institutions in 120 developing countries

\section{Other Resources}

\section{INASP Directory of Free and Open Access Online Resources}

There are many free, high- quality information resources available on the Internet. This listing provides links to some of them.

\section{SciELO}

SciELO is a collection of journals published by Latin America and Spain, available free online. There are 5 country collections and a Public Health Collection.

The above-mentioned resources are provided free to Sudan for research organizations and universities. There are more or less information resources available for every country listed in list of eligible countries.

Apart from this list, there are also more information resources available to every country in the third world. All resources are freely available on the web in all scientific areas. These resources are available to all users over the world without a subscription. It would be better to cite the link to this page due to the vast number of freely accessible e-journals on that site. http://www.inasp.info/peri/free.shtml

Here is just a sample of free e-journals available on the Internet. For more information about these resources, the INSP website can be consulted.

- AGORA (Access to Global Online Research in Agriculture) 
Action Plan Towards the Information Society in Developing Countries and the Arabic Speaking World

- Bio online International is a not-for-profit electronic publishing service committed to providing access to quality research journals published in developing countries

- Electronic Journals Library is a service offered by the University Library of Regensburg to facilitate the use of scholarly journals on the Internet. At the moment, it contains 19540 titles, among them 2195 online-only journals, covering all subjects.

- E-LIS is an open access archive for scientific or technical documents, published or unpublished, on Librarianship, Information Science and Technology, and related disciplines.

- Free For All: is a consortium of North American libraries that provides free journal articles to patrons/ librarians in developing and less developed nations.

It is worth to mention in this context that there are also several information resources available on the web through Subjects Gateways and Virtual Libraries. These are mentioned in Chowdhury paper which published in 2004 titled Digital divide: How can digital libraries bridge the gap? (Chowdhury, 2004) has pointed to several subject gateways that are very useful if information professionals involved in building the local digital library choose the appropriate one and make it accessible to their users by pointing to the website from their own page.

\section{CONCLUSION}

The transition to an information society is a compulsory corridor and not a matter of choice. The issue today is how to accomplish this with less cost and as soon as possible. Developing countries have to go through this corridor and have to embark the implementation of developing their ICTs infrastructure and drawing information policies that assure the exploitation of information resources to the optimum to increase the national productivity by utilizing information infrastructure. Improving IT for education and research environment will create new business and facilitate the IT industry. This in its turn, will foster related human development and enhance the total economy of developing countries.

\section{REFERENCES}

Armes, W. (2000). Digital libraries. Cambridge: MIT Press.

Britannica. (2006). Encyclopedia Britannica: Book of the year. London, Chigaco: Britannica INL.

Chowdhury, G. (2004). Digital library research: issues and trends. Retrieved from http://Periodicals/OJIN/ TableofContent/TheDigital libraryhow.htm..

Daveri, F. (2011). information technology and growth in Europe. Parma: University of parma.

Derrick, v. G. (2013). information technology and economic performance: A critical review of the empirical evidence. ACM computing , 35.

ESCWA. (2014). Shaping the digital future of the Arab world. New York: UN publications.

Gray, J. (2011). National information policies: problems and progress. London: Mansell publishing.

ICT for developing countries the engineering without borders. (n.d.). Retrieved December 22, 2012, from http:// www.science.unitn.it/ isf-ict/slides/ICTfordevelopingcountries.pdf

Internet world state. (n.d.). Retrieved April 07, 2017, from http://www.internetworldstats.com

Kight, A. (n.d.). Internet publishing and digital rights: The changing balance between access and ownership. Retrieved March 30, 2014, from http://www.csa.com/discoveryguides/internet/overview.php 
Action Plan Towards the Information Society in Developing Countries and the Arabic Speaking World

Mobile Man glossary. (n.d.). Retrieved January 14, 2017, from mobileman.projects.supsi.ch/glossary.html

Olan, M. (2002). Information technology in developing world. London: Consortium computing sciences.

Parliamentary office for science and technology. (n.d.). ICt in developing countries. Retrieved March 19, 2016, from www.science.unitn.it/ isf_ict/slides/ict for developing countries.pdf

Ruthven, I. (n.d.). Delivering ICT resources for the voluntary and community sector. Retrieved November 24, 2015, from http://www.icthub.org.uk/articles/Digital_Divide.html

Sjaak, H. (2005). Shaping the new digital world. New library world, 106.

Susan, R. (n.d.). The digital divide and academic achievements. The electronic library , 24, pp. 20-31.

United Nations. (2012). The least developed countries report. Retrieved April 03, 2016, from http://www.unctad. org/Templates/Webflyer.asp?docid=2026\&intItemID=1397\&lang=1

United Nations. (2008). United Nations conference on trade and development. Retrieved Novemebr 21, 2016, from http://www.unctad.org/Templates/StartPage.asp?intItemID $=2068$

Witten, I. (2006). Digital libraries for the developing world. Chicago: Interactions.

World summit on the information society. (2006). Retrieved October 16, 2016, from http://www.itu.int/wsis/ docs2/tunis/off/7.html.

Citation: Dr. Ramadan Elaiess, "Action Plan Towards the Information Society in Developing Countries and the Arabic Speaking World". American Research Journal of Computer Science and Information Technology, Volume 2, 2017; pp:1-18.

Copyright (c) 2017 Dr. Ramadan Elaiess, This is an open access article distributed under the Creative Commons Attribution License, which permits unrestricted use, distribution, and reproduction in any medium, provided the original work is properly cited. 